\title{
FENOLİK BİLEŞİKLERİN ALIÇ MEYVESİNDEN (Creategus monogyna) MİKRODALGA VE ULTRASES DESTEKLİ YÖNTEMLER İLE EKSTRAKSIYYONU
}

\author{
Merve Silanur Yılmaz ${ }^{1 *}$, Naciye Kutlu², Gizem Melissa Erdem, \\ Özge Şakıyan ${ }^{1}$, Aslı İşci $^{1}$ \\ ${ }^{1}$ Ankara Üniversitesi, Gı1da Mühendisliği Bölümü, Ankara, Türkiye \\ ${ }^{2}$ Bayburt Üniversitesi, Gıda İşleme Bölümü, Bayburt, Türkiye
}

Geliş / Received: 21.01.2021; Kabul / Accepted: 02.07.2021; Online bask1 / Published online: 14.07.2021

Yılmaz, M.S., Kutlu, N., Erdem, G.M., Şakıyan, Ö., İşçi, A. (2021). Fenolik bileşiklerin alıç meyvesinden (Creategus monogyna) mikrodalga ve ultrases destekli yöntemler ile ekstraksiyonu. GIDA (2021) 46 (4) 1002-1015 doi: 10.15237/gida.GD21018

Yılmaz, M.S., Kutlu, N., Erdem, G.M., Şakiyan, Ö., Issçi, A. (2021). Extraction of phenolic compounds from hawthorn fruit (Creategus monogyna) using microwave and ultrasound assisted methods. GIDA (2021) 46 (4) 1002 1015 doi: 10.15237/gida.GD21018

\section{ÖZ}

Bu çalışmada, alıç meyvesinden mikrodalga (MDE) ve ultrases destekli ekstraksiyon (UDE) yöntemleri kullanılarak, fenolik maddeler ekstrakte edilmiştir. MDE yöntemi, farklı katı oranları, farklı ekstraksiyon süreleri ve farklı mikrodalga güçlerinde, UDE yöntemi ise, farklı katı oranları ve sonikasyon sürelerinde uygulanmıştır. Maserasyon yöntemi kontrol grubu olarak kullanılmıştır. Maserasyon, MDE ve UDE yöntemleriyle elde edilen ekstraktların toplam fenolik madde (TFM) miktarları ve renk değerleri belirlenmiştir. En yüksek TFM miktarları MDE, UDE ve maserasyon yöntemlerinde sirasıyla 9.31, 5.34 ve $3.00 \mathrm{mg} \mathrm{GAE} / \mathrm{g}$ kuru madde olarak bulunmuştur. Bu sonuçlara göre MDE yöntemi ile elde edilen miktar, UDE ve maserasyona kiyasla sırasıyla 1.7 ve 3.1 kat daha fazladır. Bunun yanında MDE ile elde edilen L* değerlerinin daha düşük olduğu görülmüştür. Sonuç olarak, MDE yönteminin, alıç meyvesinden fenolik madde ekstraksiyonu için en uygun yöntem olduğu tespit edilmiştir.

Anahtar kelimeler: Alıç, mikrodalga destekli ekstraksiyon, ultrases destekli ekstraksiyon, fenolik madde

\section{EXTRACTION OF PHENOLIC COMPOUNDS FROM HAWTHORN FRUIT (Creategus monogyna) USING MICROWAVE AND ULTRASOUND ASSISTED METHODS}

\section{ABSTRACT}

In this study, phenolic compounds were extracted from hawthorn fruit using microwave (MAE) and ultrasound assisted extraction (UAE) methods. The MAE was applied at different solids ratios, different extraction times and different microwave powers. UAE was applied at different solids ratios

\footnotetext{
* Yazışmalardan sorumlu yazar/Corresponding author;

Merve Silanur YıImaz; ORCID no:0000-0002-3184-1780

Naciye Kutlu; ORCID no: 0000-0002-4075-8823

Gizem Melissa Erdem; ORCID no:0000-0002-7855-9096

Özge Şakıyan; ORCID no: 0000-0002-0778-8211

Aslı İsci; ORCID no: 0000-0002-8319-0414
}

$\triangle$ merveyilmaz@ankara.edu.tr $\quad$ (1) (+90) $3122033300 / 3642$

鸟(+90) 3123178711 
and sonication times. The maceration method was used as the control group. Total phenolic content (TPC) and color values of the extracts were examined. The highest values of TPC were determined as 9.31, 5.34, and $3.00 \mathrm{mg} \mathrm{GAE} / \mathrm{g}$ dry matter in MAE, UAE, and maceration methods, respectively. Based on these results, it was found that the TPC value of the MAE method was 1.7 and 3.1-fold more than those of UAE and maceration, respectively. In addition, it was observed that $\mathrm{L}^{*}$ values of MAE samples were lowest among others. It was concluded that the MAE is the most suitable method for the extraction of phenolic compounds from hawthorn fruit.

Keywords: Hawthorn, microwave assisted extraction, ultrasound assisted extraction, phenolic compounds

\section{GİRİŞ}

Alıç, Rosaceae familyasının Crataegus cinsindeki tüm bitki türlerinin ortak adıdır. Türkiye'de birçok bölgede özellikle dağlık alanlarda yetişmektedir (Seçmen vd., 1989). Her ne kadar Türkiye'de yaygin olarak tüketilmesede, Çin ve Avrupa ülkelerinde bitkisel ilaç olarak, çeşitli kardiyovasküler hastalıkların tedavisinde kullanilmaktadır (Chang vd., 2002).

Alıç meyvesi, insan sağlığına yararlı olan mineralleri içermektedir. Bu minerallerin başında $\mathrm{Ca}, \mathrm{P}, \mathrm{K}, \mathrm{Fe}$ ve $\mathrm{Mg}$ gelmektedir. Bunların yanında alıç meyvesi, önemli derecede karbonhidrat, şeker ve vitamin içermektedir (Özcan vd., 2005). Ek olarak alıç meyvesi, apijenin, kuersetin, klorojenik asit, gallik asit, viteksin, kumarik asit, kafeik asit, narinjenin ve kratenasin gibi fenolik maddeler bakımından da oldukça zengindir (Çoklar vd., 2018). Fenolik maddeler, insan sağlığı açısından oldukça önemli olan sekonder metabolitlerdir (Lapornik vd., 2005). Bu maddeler, bitki büyümesi ve üremesinde patojenlere karş1 etkili bir koruma sağlamakta, meyve ve sebzelerin renk ve duyusal özelliklerine katkıda bulunmaktadırlar (Popa vd., 2008; Ignat vd., 2011).

Geleneksel ekstraksiyon yöntemleri (maserasyon, sokslet, perkolasyon vb.), yüksek enerji tüketimi, uzun süren ekstraksiyon süresi, biyoaktif bileşiklerin degradasyonu ve yüksek çözücü tüketimi gibi dezavantajlara sahiptirler. $\mathrm{Bu}$ dezavantajları ortadan kaldırmak ve aynı zamanda ekstraksiyon verimini arttırmak için, mikrodalga ve ultrases destekli ekstraksiyon gibi yenilikçi yöntemlerin kullanımı son y1llarda önemli derecede artmıştır (Chemat vd., 2011; Kaderides vd., 2019).
Mikrodalga destekli ekstraksiyon, gida materyallerinden fenolik maddelerin eldesinde, son yillarda yaygin olarak kullanilmaktadir. Yüksek frekanslı elektromanyetik dalgalara sahip olan mikrodalganın çalışma prensibi, iyonik iletim ve dipol rotasyona dayanmaktadır (Xia vd., 2013; Nitthiyah vd., 2017; Meda vd., 2017). İyonik iletim, iyonların elektrik alanın etkisi alında göç etmesine ve is1 üretme kabiliyeti olarak tanımlanmaktadır. Dipol rotasyon ise su moleküllerinin yüksek frekansta elektrik alanı içinde hareketine bağlı olarak, materyal içinde 1s1 oluşturmasına dayanmaktadır (Fanari vd., 2020). Mikrodalga destekli ekstraksiyonda, elektromanyetik dalgalar ekstraksiyon işlemi sırasında çözücü ve örneğin 1sınmasını sağlar. Bu yöntemde, ekstraksiyon işlemi için seçilen çözücünün mikrodalga enerjisini absorblama yeteneği ve örnek ile çözelti arasındaki etkileşim çok önemlidir (Lopez-Avila, 1999). Geleneksel yöntemlerle yapilan ekstraksiyonlar ile kıyaslandığında, mikrodalga destekli ekstraksiyon yöntemi, düşük çözücü tüketimi, zaman tasarrufu ve yüksek ekstraksiyon verimi gibi avantajlara sahiptir (Lovrić vd., 2017). Son zamanlarda yapilan çalışmalar incelendiğinde, mikrodalga destekli ekstraksiyonun, muz kabuklarından pektin eldesinde (Swamy ve Muthukumarappan, 2017), kurutulmuş paçuli yaprakları ve adaçayından uçucu yağ eldesinde (Kusuma vd., 2018; Wei vd., 2018), kahve telvesi ve nar kabuklarından polifenol eldesinde (Kaderides vd., 2019; Pettinato vd., 2019) kullanıldı̆̆g görülmüştür.

Is1l olmayan gida muhafaza yöntemleri kullanımıyla, gıdalarda isıl işlem ile birlikte ortaya çıkan kalite kayılarının azaltılması amaçlanmaktadır. Ultrases destekli ekstraksiyon da bu amaçla kullanılan yöntemlerden biridir 
(Baysal ve İçier, 2012). Ultrases, ses dalgalarının saniyede 20.000 ve daha fazla titreșmesi sonucu oluşmaktadır. Gıda teknolojisinde kullanılan ultrases ekipmanlar1 $20 \mathrm{kHz}-10 \mathrm{MHz}$ frekans aralığında değişmektedir (Knorr vd., 2004). Ultrases destekli ekstraksiyon işlemi kavitasyon olgusu ile ilişkilendirilmektedir. Ultrases etkisindeki sıvilarda, mikro kabarcıkların oluşması, genleşmesi ve patlaması sonucu ortaya ç1kan bu olaya "akustik kavitasyon" ad1 verilmektedir (Piyasena vd., 2003). Patlama ile kabarcığın etrafinda, $5500{ }^{\circ} \mathrm{C}$ ye ve $50 \mathrm{MPa}$ ulaşan çok yüksek sıcaklık ve basınç bölgeleri oluşmaktadır (Pico, 2013). Ultrases teknolojisi ile oluşan bu kavitasyon nedeniyle, materyalin hücre duvarları parçalanmakta, çözücünün ürüne penetrasyonu artmakta ve böylece kütle transferi olumlu yönde etkilenmektedir (Awad vd., 2012). Son zamanlarda yapılan çalışmalar incelendiğinde, ultrases destekli ektraksiyonun, kakao çekirdeği (Quiroz-Reyes vd., 2013), siyah çay (Both vd., 2014), mor tatli patates (Zhu vd., 2016), patates kabuklar1 (Kumari vd., 2017) ve portakal posas1 (Ghasempour vd., 2019) gibi farklı materyallerde biyoaktif bileşiklerin eldesinde kullanıldığı görülmüştür.

$\mathrm{Bu}$ çalışmada, alıç meyvesinden (Crataegus monogyna) farklı proses koşullarında (güç, süre ve kat1 oran1) mikrodalga ve ultrases destekli yöntemler kullanılarak, fenolik maddeler ekstrakte edilmiştir. Maserasyon yöntemi ise kontrol grubu olarak kullanılmıștır. Farklı yöntemler ile elde edilen ekstrakların toplam fenolik madde miktarları ve renk değerleri karşılaştırılmış olup, sonuçlara göre alıç meyvesi için en uygun ekstraksiyon yöntemi belirlenmiştir.

\section{MATERYAL VE YÖNTEM}

\section{Materyal}

Çalışmada kullanılan alıç meyvesi (Crataegus monogyna), hasat döneminde (Eylül ve Ekim ayları), Ankara ilinin Gölbaşı ilçesindeki, yerel üreticiden temin edilmiştir. Alıç meyvesi, öncelikle sap ve çekirdeklerinden ayrılmış, daha sonra maksimum $5 \mathrm{~mm}$ çapında olacak şekilde, küçük parçalar haline getirilmiştir. Depolama sırasında dışarıdan nem almaması için, 18x23 ebatlarındaki vakum poşetlere konularak, vakum paketleme (Stilea, VM 501, Çin) yapılmış ve analizlerde kullanılmak üzere $-18{ }^{\circ} \mathrm{C}$ 'de muhafaza edilmiştir. Alıç meyvesinin başlangıç nem değeri kızılötesi nem tayin cihazı (MA 150, Sartorius, Almanya) ile belirlenmiş ve $\% 68 \pm 0.92$ olarak ölçülmüştür.

\section{Maserasyon}

Maserasyon yönteminde iki farklı katı oranında $(\% 5 \mathrm{w} / \mathrm{v}$ ve $\% 10 \mathrm{w} / \mathrm{v})$ hazırlanan örnekler 24 saat boyunca $25{ }^{\circ} \mathrm{C}$ 'de bekletilmiştir (Xu vd., 2017). Çözücü olarak su kullanılmış ve bu yöntem ile elde edilen sonuçlar, kontrol grubu olarak değerlendirilmiştir. Elde edilen ekstraktlar, amber renkli şişelere konulmuş olup, fiziksel ve kimyasal analizler yapilincaya kadar $-18{ }^{\circ} \mathrm{C}$ 'de muhafaza edilmiştir.

\section{Mikrodalga destekli ekstraksiyon}

Alıç meyvesi, ev tipi bir mikrodalga firınına 3 kademeli bir soğutucu entegre edilerek oluşturulan mikrodalga ekstraksiyon sistemi (GMOM 25, General Electric, ABD) ile ekstrakte edilmiştir. Kullanılan mikrodalga ekstraksiyon sisteminin şematik diyagramı Şekil 1'de verilmiştir. Çözücü olarak su kullanılmıştır ve çalışmada kullanılan proses koşulları ön denemeler ile belirlenmiştir. Ektraksiyon, farklı kat1 oran1 $(\% 5 \mathrm{w} / \mathrm{v}$ ve $\% 10 \mathrm{w} / \mathrm{v})$, farkl1 mikrodalga gücü $(180,270$ ve $360 \mathrm{~W})$ ve farklı ekstraksiyon sürelerinde $(5,10,20,30 \mathrm{dk}$.) uygulanmıştır. Örnekler $30 \mathrm{~mL}$ çözücü içerisinde balonjojede karıștırılarak mikrodalga fırına konulmuştur. Mikrodalga ekstraksiyonu sonunda, ekstrakların sicaklık değerleri $80 \pm 4{ }^{\circ} \mathrm{C}$ olarak ölçülmüștür. İsslem sonrasında örnek+çözücü karışımı, kaba filtre kağıdından süzülerek, katı partiküllerinden ayrılmışıtır. Elde edilen ekstraktlar, amber renkli şişelere konulmuş olup, fiziksel ve kimyasal analizler yapilıncaya kadar -18 ${ }^{\circ} \mathrm{C}$ 'de muhafaza edilmiştir.

\section{Ultrases destekli ekstraksiyon}

Ekstraksiyon, farklı katı oran $1 \% 5 \mathrm{w} / \mathrm{v}$ ve $\% 10$ $\mathrm{w} / \mathrm{v})$ ve farklı sonikasyon sürelerinde $(1,10,20$, 30, 50, $70 \mathrm{dk}$.), $50{ }^{\circ} \mathrm{C}$ sicakliktaki ultrases banyoda (RK 100 H, Bandelin Sonorex, Almanya) yapılmıştır. Yapılan ön denemelerde, çalışmada kullanilan ultrasonik banyonun $50{ }^{\circ} \mathrm{C}$ civarında 
oldukça stabil kaldığ1 gözlenmekle birlikte, sıcaklık artışı olmaması adına gerektiği durumlarda, $50{ }^{\circ} \mathrm{C}$ 'de sabit tutabilmek için gerektiğinde banyoya buz eklemesi yapılmıştır. Ultrasonik banyo içine çözücü hacmi $100 \mathrm{~mL}$ olacak şekilde örnek yerleştirilmiştir. Çözücü olarak su kullanılmıştır. İşlem sonrasında örnek+çözücü karışımı, kaba filtre kağıdından süzülerek katı partiküllerden ayrılmıştır. Elde edilen ekstraktlar, amber renkli şişelere konulmuş olup, fiziksel ve kimyasal analizler yapilıncaya kadar $-18{ }^{\circ} \mathrm{C}$ 'de muhafaza edilmiştir.

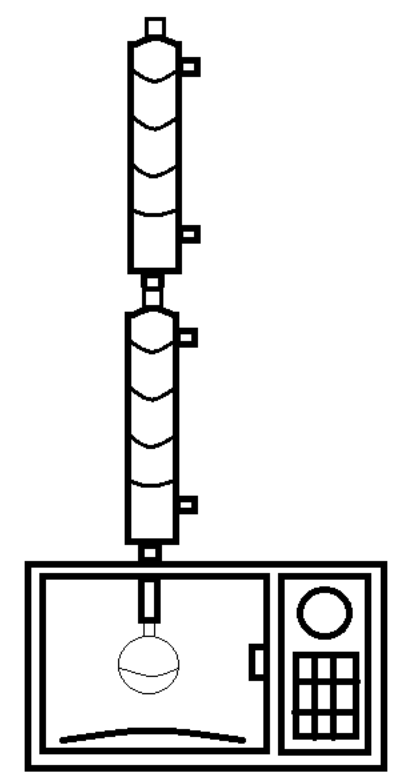

Şekil 1. Mikrodalga ekstraksiyon sisteminin şematik diyagram 1

Figure 1. Schematic diagram of microwave-assisted extraction

\section{Nem tayini}

Alıç örneklerinin nem içeriği, kızılötesi nem tayin cihaz1 (MA150, Sartorius, Germany) ile belirlenmiştir.

\section{Toplam fenolik madde (TFM) miktarının belirlenmesi}

Farklı ekstraksiyon yöntemleri sonunda elde edilen ekstraktların toplam fenolik madde miktarlar1, Folin-Ciocalteu yöntemine göre belirlenmiştir (Çoklar ve Akbulut, 2016). $1 \mathrm{~mL}$ ekstrakt tüpe alınarak, üzerine $5 \mathrm{~mL}$ FolinCiocalteu çözeltisi $(1: 10)$ ve $4 \mathrm{~mL}$ sodyum karbonat- $\mathrm{Na}_{2} \mathrm{CO}_{3} \quad(\% 7.5)$ çözeltisi eklenmiştir. Hazırlanan tüpler oda sicaklığında, karanlık bir ortamda 2 saat bekletilmiştir. Süre sonunda UVVIS spektrofotometrede (Lambda35, Perkin Elmer, ABD) $765 \mathrm{~nm}$ dalga boyunda absorbans değerleri ölçülmüştür. Gallik asit referans madde olarak kullanılmıştır ve sonuçlar mg Gallik Asit Eşdeğeri (GAE)/g kuru madde olarak verilmiştir. Analizler iki tekerrürlü olarak yapılmıştır.

\section{Renk değerlerinin belirlenmesi}

Farklı ekstraksiyon yöntemleri sonunda elde edilen ekstraktların renk değerleri, CIE sistemi esasına dayanarak, kolorimetre yardımıla (Konica Minalta, C-400, Japonya) ölçülmüştür. Sıv1 fazda bulunan ekstraktların renk ölçümleri için özel yapılmış ölçüm kabı kullanılmıştır. Ölçüm parametrelerinden $L^{*}$ değeri açıllıkkoyuluk, a* değeri kırmızılık-yeşillik ve b* değeri sarılık-mavilik, kroma değeri $\left(C^{*}\right)$ matlık-canlılık, Hue değeri $\left(\mathrm{h}^{\circ}\right)$ renk açısı ve $\Delta \mathrm{E}$ değeri toplam renk farkı hakkında bilgi vermektedir (Akbulut ve Çoklar, 2008).

\section{İstatiksel analiz}

Bulgulara yönelik istatistiksel analizler, MINITAB 17.1.1.0 (Minitab, State Collage, PA, ABD) paket programı kullanılarak gerçekleştirilmiştir. Bağımlı değişkenler arasındaki farklılık, ANOVA-Tukey testi ile $P \leq 0.05$ önem derecesine göre belirlenmiştir.

\section{SONUÇLAR VE TARTIŞMA}

Toplam fenolik madde miktarı

Farklı mikrodalga güçlerinde (180, 270 ve 360 W), ekstraksiyon sürelerinde ve katı oranlarında (\%5 ve \%10), mikrodalga destekli ekstraksiyon ile elde edilen ekstraktların TFM miktarlarındaki değişim Şekil 2 ve Şekil 3’te verilmiştir. \%5 katı oranı için aynı ekstraksiyon sürelerinde, artan mikrodalga gücüne bağlı olarak, elde edilen TFM miktarları arasındaki fark istatistiksel açıdan önemli bulunmamıştır ( $P$ >0.05). Ayrıca, \%5 katı oranında ve $180 \mathrm{~W}$ mikrodalga gücünde işlem gören örnekler için, ekstraksiyon süresindeki değişimin TFM miktarı üzerine istatiksel olarak bir etkisi görülmemiştir $(P>0.05)$. Bunun yanı sıra, $\% 5$ katı oranında, 270 ve $360 \mathrm{~W}$ mikrodalga güçlerinde yapılan ekstraksiyon işlemi sonucu elde 
edilen ekstraktlarda ise ekstraksiyon süresindeki artışı TFM miktarı üzerine etkili olduğu tespit edilmiştir $(P<0.05) . \% 10$ katı oranında ise, aynı ekstraksiyon süresinde mikrodalga gücündeki değişimin TFM miktarı üzerine istatistiksel olarak önemli bir etki göstermediği bulunmuştur $(P$ $>0.05)$. Her iki katı oranı için (\%5 ve $\% 10)$ TFM miktarları incelendiğinde, en yüksek değerin (9.31 $\pm 0.15 \mathrm{mg}$ GAE/g kuru madde), \%5 kat1 oranında, mikrodalga gücünün $270 \mathrm{~W}$ ve ekstraksiyon süresinin 20 dakika olduğu proses koşullarında elde edildiği tespit edilmiştir. Bunlara ek olarak, kat1 oranı ve mikrodalga gücü interaksiyonunun toplam fenolik madde miktar1 üzerine etkili olduğu $(P<0.05)$ görülmüştür. $\mathrm{Bu}$ bulguya göre, katı başına düşen çözücü miktarı artırıldığında, TFM eldesinde de önemli bir artış olduğu söylenebilir. Çözücü miktarındaki artış ile hücrelere daha fazla çözücü nüfuz etmekte ve dolayıs1 ile daha yüksek miktarda TFM eldesi mümkün olmaktadır ve bu durum birçok araștırıcı tarafindan da rapor edilmiştir. Örneğin, Alifak1 (2019) gilaburu meyvesinden farklı mikrodalga gücü (90-450 W), farklı ekstraksiyon süresi (1-120 dakika) ve farklı katı:çözücü oranında (5:10015:100 $\mathrm{g} / \mathrm{mL}$ ), toplam fenolik madde ekstraksiyonu gerçekleştirmiştir. En yüksek TFM miktar1 (yaklaşık $70 \mathrm{mg} / \mathrm{g}$ kuru madde), çözücü miktarının en yüksek olduğu $5: 100 \mathrm{~g} / \mathrm{mL}$ katı:çözücü oranında elde edilmiştir. Yeşilören Akal (2019) siyah havuç posasindan mikrodalga destekli ektraksiyon yöntemi ile fenolik bileşik eldesi üzerine çalışmıştır. Sonuçta bizim çalışmamıza benzer olarak, kullanılan birim katı başına düşen çözücü miktarının 2 katına çıkarılması ile TFM ekstraksiyonunda $\% 17$ artış sağlandığ1 rapor edilmiştir.

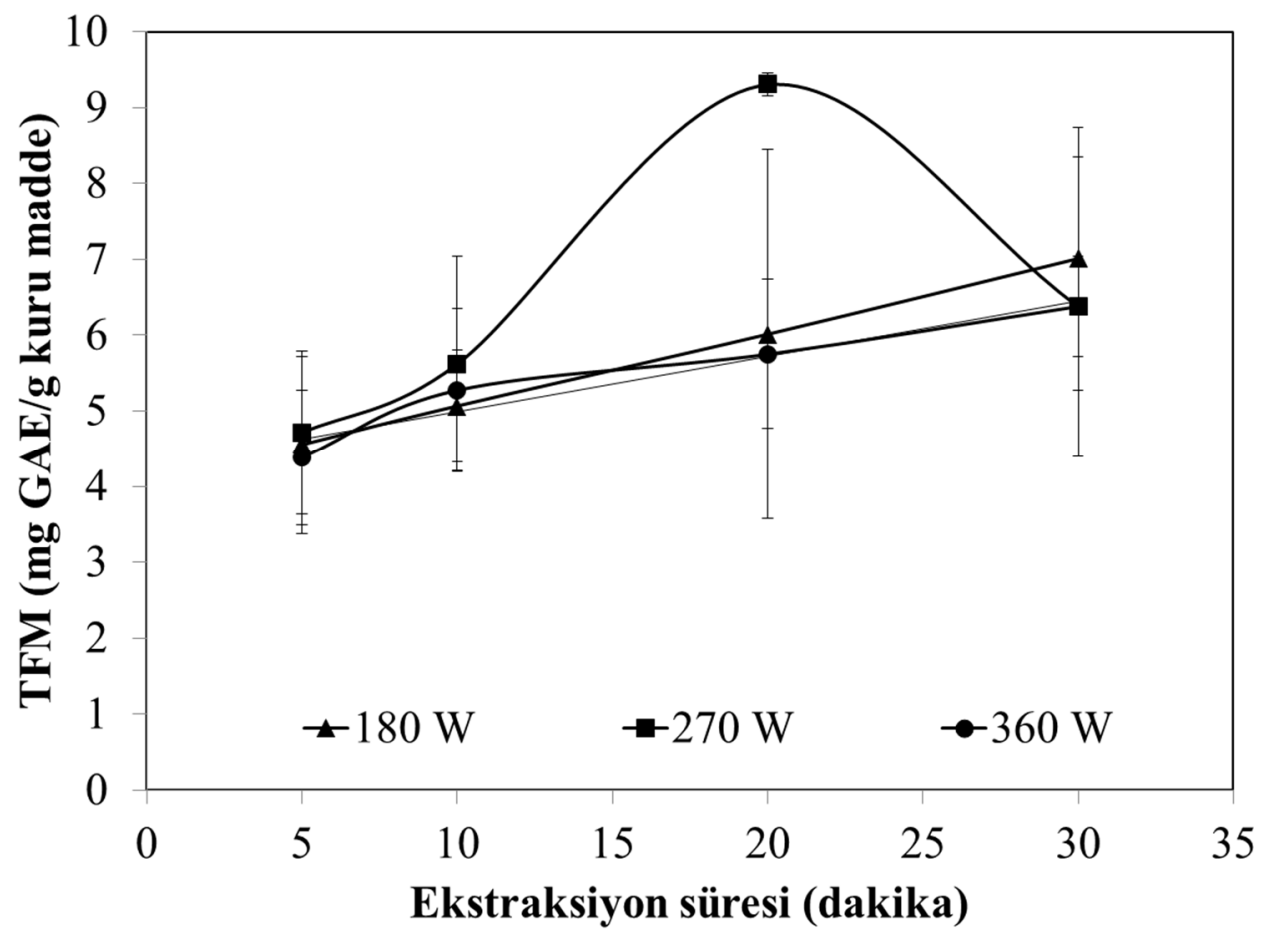

Şekil 2. MDE ile elde edilen örneklerin TFM miktarının mikrodalga gücü (180, 270 ve $360 \mathrm{~W})$ ve ekstraksiyon süresi (5, 10, 20 ve $30 \mathrm{dk}$.) ile değişimi ( $\% 5$ katı oranında)

Figure 2. Variation of TPC of MAE samples with respect to microwave power (180, 270 and $360 \mathrm{~W})$ and extraction time $(5,10,20$ ve $30 \mathrm{~min}$.) (for $5 \%$ solid ratio) 


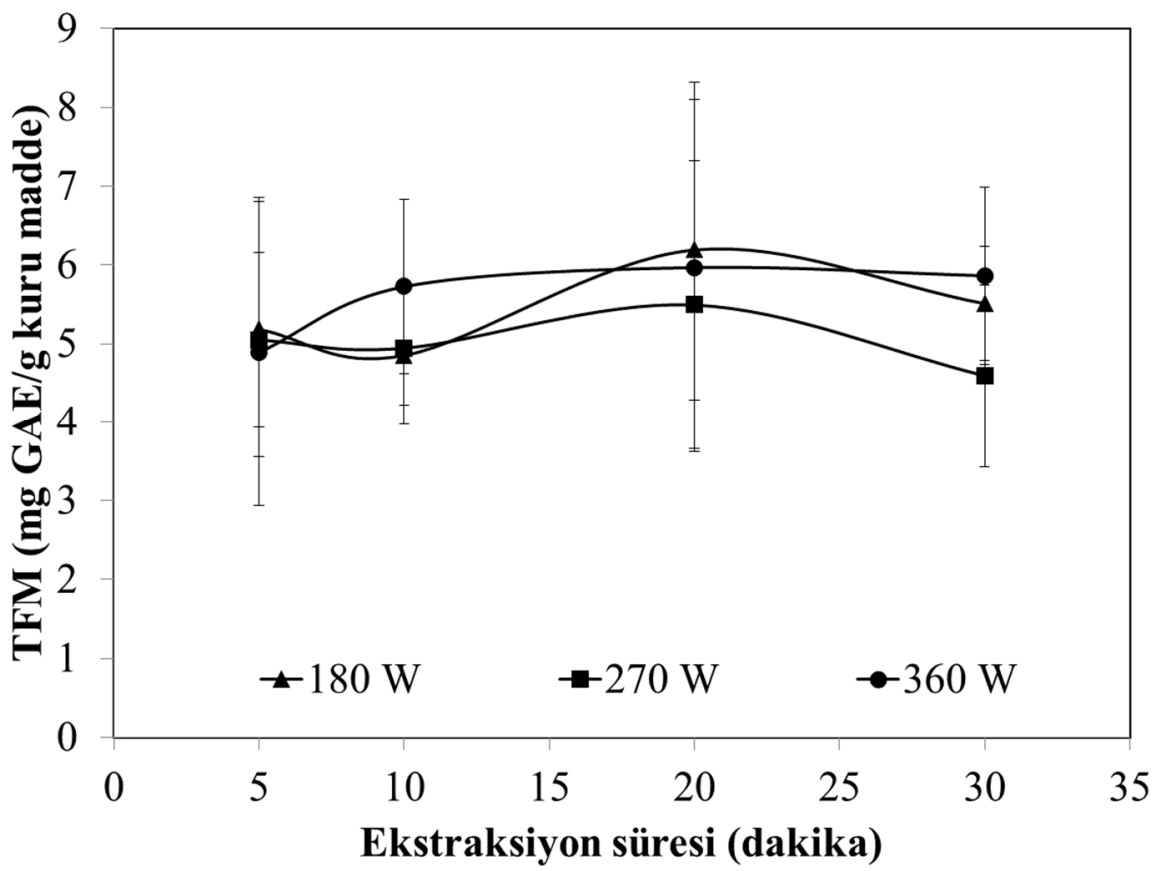

Şekil 3. MDE ile elde edilen örneklerin TFM miktarının mikrodalga gücü (180, 270 ve $360 \mathrm{~W}$ ) ve ekstraksiyon süresi $(5,10,20$ ve $30 \mathrm{dk}$.) ile değişimi (\%10 katı oranında)

Figure 3. V ariation of TPC of MAE samples with respect to microwave power (180, 270 and $360 \mathrm{~W})$ and extraction time (5, 10, 20 ve 30 min.) (for 10\% solid ratio)

Özbek vd. (2018) yapmış oldukları çalışmada, farklı mikrodalga güçlerinde (170-280 W) fistık kabuğundan toplam fenolik madde ekstraksiyonu gerçekleştirmişlerdir ve optimum verimin elde edildiği mikrodalga gücünü, $250 \mathrm{~W}$ olarak bildirmişlerdir. $\mathrm{Bu}$ çalışmada da yüksek mikrodalga gücünün TFM miktarı üzerine pozitif etkisi görülmemiştir.

Ultrases destekli ekstraksiyon yöntemi ile elde edilen örneklerin TFM miktarlarının, farklı sonikasyon süreleri $(1,10,20,30,50$ ve $70 \mathrm{dk}$.) ve katı oranları (\%5 ve $\% 10)$ ile değişimi Şekil 4 'te verilmiştir. Elde edilen sonuçlar incelendiğinde, iki farklı katı oranında da sonikasyon süresinin artmasıyla TFM miktarının arttığı gözlenmiştir $(P$ $<0.05)$. Bu durum artan sonikasyon süresi ile daha fazla fenolik maddenin çözünerek çözücüye geçmesinden kaynaklanmaktadır. UDE yönteminde, en yüksek toplam fenolik madde miktar1 (5.34 $\pm 0.68 \mathrm{mg}$ GAE/g kuru madde), kat1 oranının $\% 5$ ve sonikasyon süresinin 70 dakika olduğu proses koşullarında elde edilmiştir. Her iki katı oranında da yapılan ekstraksiyon işleminde, 30. dakikadan sonra MDE yöntemi ile elde edilen sonuçlara benzer olarak, birim katı başına düşen çözücü miktarı arttıkça, TFM miktarının arttığı görülmüş̧ür, ancak bu artış istatistiksel açıdan önemli bulunmamıştır $(P>0.05)$. Bu sonuçtan yola çıkılarak çözücü oranındaki artısıı, ekstraksiyon hizı üzerinde etkili olduğu söylenebilir. Alifak1 vd. (2018) gilaburu meyvesinde farklı katı:çözücü oranlarında (5:100, 10:100, 15:100) ultrases destekli ekstraksiyon ile TFM eldesi üzerine çalışışlardır. Çalışma sonucunda, bu çalışmada bulunan sonuçlara benzer olarak, birim katı başına düşen çözücü miktarının artması ile TFM veriminin arttığını bildirmişlerdir. Khan vd. (2010) tarafindan yapılan bir çalışmada, portakaldan maserasyon ve ultrases destekli ekstraksiyon yöntemleri ile polifenoller ekstrakte edilmiştir. Çalışma sonucunda ise TFM miktarı ve ekstraksiyon veriminin ultrases destekli ekstraksiyon yöntemi ile daha yüksek olduğu rapor edilmiştir. 


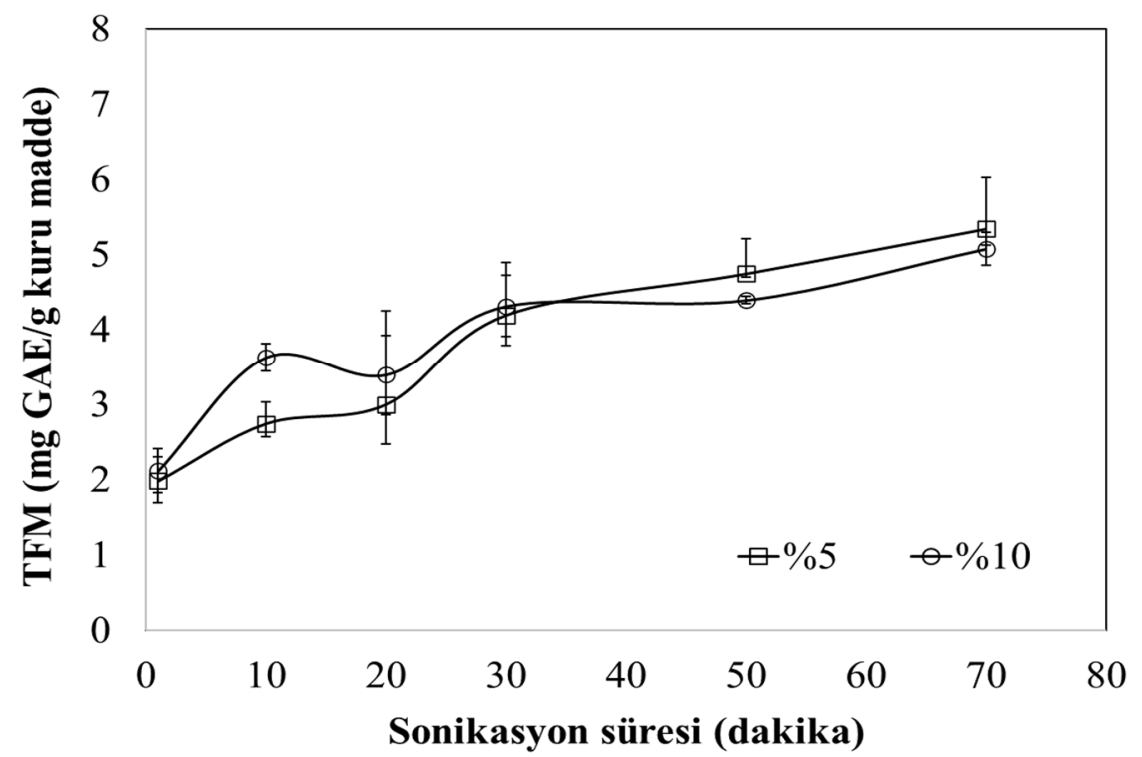

Şekil 4. UDE ile elde edilen örneklerin TFM miktarının sonikasyon süresi (1, 10, 20, 30, 50 ve 70 dk.) ve katı oranı $(\% 5$ ve $\% 10)$ ile değişimi

Figure 4. Variation of TPC of UAE samples with respect to sonication time (1, 10, 20, 30, 50 and 70 min.) and solid ratios $(5 \%$ and $10 \%)$

MDE ve UDE yöntemleri ile edilen en yüksek TFM miktarlar1 s1rası ile $9.31 \pm 0.15$ (kat1 oranı: $\% 5$, mikrodalga gücü: $270 \mathrm{~W}$, süre: 20 dakika) ve $5.34 \pm 0.68 \mathrm{mg}$ GAE/g kuru madde (kat1 oranı: $\% 5$, süre: 70 dakika) olarak bulunmuştur. Kontrol grubunda ise TFM miktarı $\% 5$ katı oranı için $3.00 \pm 0.10 ; \% 10$ katı oranı için $2.49 \pm 0.15 \mathrm{mg}$ GAE/g kuru madde olarak hesaplanmıştır. Bu sonuçlara göre, hem elde edilen TFM miktarı hem de ekstraksiyon süresi açısından $\mathrm{MDE}$ yönteminin, maserasyon ve UDE yöntemine göre daha iyi olduğu söylenebilir. MDE yönteminin veriminin yüksek olmasının nedeni mikrodalgaların hacimsel isıtma özelliğinde olmasıdır. Aynı zamanda MDE yöntemi ile elde edilen ekstraklarda ölçülen son sıcaklığın $(\sim 80$ $\left.{ }^{\circ} \mathrm{C}\right)$, maserasyon $\left(25^{\circ} \mathrm{C}\right)$ ve $\operatorname{UDE}\left(50{ }^{\circ} \mathrm{C}\right)$ yöntemine göre daha yüksek olmasindan da kaynaklandığı düşünülmektedir. $\mathrm{Bu}$ sonuçlara benzer olarak Dahmoune vd. (2014) sakız ağac1 yapraklarından, Radojkovic vd. (2018) karadut yapraklarından, Baltacıoğlu vd. (2019) şeftali posasından fenolik maddelerin ekstraksiyonu için MDE ve UDE yöntemlerini kullanmışlar ve MDE yöntemi ile daha yüksek TFM ekstrakte edildiğini bildirmişlerdir. Pan vd. (2003) tarafindan yapılan bir çalışmada, yeşil çay yapraklarından çay polifenollerini ve çay kateşinlerini, maserasyon, mikrodalga ve ultrases destekli ekstraksiyon yöntemleri ile ekstrakte etmişlerdir. Çalışma sonucunda, MDE yönteminin, ekstraksiyon süresi, ekstraksiyon verimi ve ekstrakte edilen polifenol ile kateşin miktarları açısından daha etkili olduğu sonucuna varmıșlardır.

\section{Renk}

Mikrodalga destekli ekstraksiyon yöntemi ile elde edilen ekstraklara ait renk değerleri Çizelge 1'de verilmiştir. Yapılan istatistiksel analiz sonucunda, MDE yöntemi ile elde edilen ekstraktlardaki L* değerleri üzerine katı oranının ve işlem süresinin istatistiksel olarak etkili olduğu görülmüştür ( $P$ $<0.05)$. MDE yöntemi ile elde edilen örneklerde, katı oranındaki artışla birlikte $L^{*}$ değerlerinin azaldığ1 (ekstraktların renklerinin koyulaştı̆̆1) görülmüştür. Maksimum TFM miktarı en açık renkli ekstraktta (\%5 katı oranında) elde edilmiş olması çelişkili gibi görünse de bu durum toplam fenolik bileşik miktarı sonuçlarının, kuru madde 
üzerinden hesaplanmasından kaynaklanmaktadır. Başka bir deyișle, çözücü miktarının fazla olması örneklerin renginin seyrelmesine ve daha açık renkte olmasina sebep olmuştur. a* değerleri üzerine katı oran1, süre ve mikrodalga gücünün etkili olduğu bulunmuştur $(P<0.05)$. b* değerleri ise sadece değişen katı oranından etkilenmiştir $(P$ $>0.05)$. $C^{*}$ ve $\Delta \mathrm{E}$ değerleri her iki katı oranı içinde ayr1 ayr1 incelendiğinde, aynı sürelerde artan mikrodalga gücüne bağlı olarak aralarındaki farkın istatistiksel açıdan etkili olmadığ1 görülmüştür ( $P$ $>0.05) . h^{\circ}$ değeri için ise $\% 5$ katı oranında, 270 ve $360 \mathrm{~W}$ mikrodalga güçlerinde, \%10 katı oranında ise sadece $360 \mathrm{~W}$ mikrodalga gücünde artan süreye bağlı olarak aralarındaki farkın istatistiksel açıdan anlamsız olduğu görülmüştür $(P>0.05)$.

Çizelge 1. MDE ile elde edilen ekstraktların $\mathrm{L}^{*}, \mathrm{a}^{*}, \mathrm{~b}^{*}, \mathrm{C}^{*}, \mathrm{~h}^{\circ}$ ve $\Delta \mathrm{E}$ değerlerinin farklı mikrodalga güçleri $(180,270$ ve $360 \mathrm{~W})$, ekstraksiyon süreleri $(5,10,20$ ve $30 \mathrm{dk}$.) ve katı oranları (\%5 ve \%10) ile değişimi

Table 1. Variation of $L^{*}, a^{*}, b^{*}, C^{*}, b^{\circ}$ and $\triangle E$ values of $M A E$ samples with respect to microwave power (180, 270 and $360 \mathrm{~W})$, extraction time (5, 10, 20 ve $30 \mathrm{~min}$.) and solid ratios (5\% and 10\%)

\begin{tabular}{|c|c|c|c|c|c|}
\hline $\begin{array}{l}\text { Renk değerleri } \\
\text { Color values }\end{array}$ & $\begin{array}{l}\text { Kat1 oran1 } \\
\text { Solid ratio }\end{array}$ & $\begin{array}{l}\text { Süre (dk.) } \\
\text { Time (min.) }\end{array}$ & $180 \mathrm{~W}$ & $270 \mathrm{~W}$ & $360 \mathrm{~W}$ \\
\hline \multirow{8}{*}{$\mathrm{L}^{*}$} & \multirow{4}{*}{$\% 5$} & 5 & $33.35 \pm 0.72^{\mathrm{a}, \mathrm{A}}$ & $31.42 \pm 0.36^{\mathrm{a}, \mathrm{AB}}$ & $31.40 \pm 0.48^{\mathrm{a}, \mathrm{A}}$ \\
\hline & & 10 & $30.64 \pm 0.00^{\mathrm{a}, \mathrm{A}}$ & $30.24 \pm 0.62^{\mathrm{a}, \mathrm{B}}$ & $31.20 \pm 0.17 \mathrm{a}, \mathrm{A}$ \\
\hline & & 20 & $31.03 \pm 0.40^{\mathrm{a}, \mathrm{A}}$ & $30.77 \pm 0.20^{\mathrm{a}, \mathrm{AB}}$ & $30.29 \pm 0.51^{\mathrm{a}, \mathrm{A}}$ \\
\hline & & 30 & $31.01 \pm 1.42^{\mathrm{a}, \mathrm{A}}$ & $32.03 \pm 0.10^{\mathrm{a}, \mathrm{A}}$ & $31.95 \pm 1.98^{\mathrm{a}, \mathrm{A}}$ \\
\hline & \multirow{4}{*}{$\% 10$} & 5 & $31.51 \pm 1.19 \mathrm{a}, \mathrm{A}$ & $27.84 \pm 0.36^{\mathrm{b}, \mathrm{A}}$ & $28.85 \pm 0.60^{a b, A}$ \\
\hline & & 10 & $28.21 \pm 0.58^{\mathrm{a}, \mathrm{A}}$ & $27.54 \pm 1.03 \mathrm{a}, \mathrm{A}$ & $29.48 \pm 1.82^{\mathrm{a}, \mathrm{A}}$ \\
\hline & & 20 & $28.29 \pm 1.12^{\mathrm{a}, \mathrm{A}}$ & $29.28 \pm 1.22^{\mathrm{a}, \mathrm{A}}$ & $29.28 \pm 1.72^{\mathrm{a}, \mathrm{A}}$ \\
\hline & & 30 & $28.98 \pm 0.31^{\mathrm{a}, \mathrm{A}}$ & $27.42 \pm 0.47 \mathrm{a}, \mathrm{A}$ & $27.60 \pm 0.88^{a, A}$ \\
\hline \multirow{8}{*}{$a^{*}$} & \multirow{4}{*}{$\% 5$} & 5 & $-0.32 \pm 0.05^{\mathrm{a}, \mathrm{B}}$ & $-0.12 \pm 0.06^{\mathrm{a}, \mathrm{A}}$ & $-0.12 \pm 0.06^{\mathrm{a}, \mathrm{A}}$ \\
\hline & & 10 & $-0.15 \pm 0.00^{\mathrm{b}, \mathrm{AB}}$ & $0.01 \pm 0.03 \mathrm{a}, \mathrm{A}$ & $-0.14 \pm 0.05^{\mathrm{b}, \mathrm{A}}$ \\
\hline & & 20 & $-0.03 \pm 0.11 \mathrm{a}, \mathrm{A}$ & $0.02 \pm 0.09 \mathrm{a}, \mathrm{A}$ & $0.04 \pm 0.02^{\mathrm{a}, \mathrm{A}}$ \\
\hline & & 30 & $-0.07 \pm 0.02^{\mathrm{a}, \mathrm{AB}}$ & $-0.07 \pm 0.08^{\mathrm{a}, \mathrm{A}}$ & $-0.12 \pm 0.23^{\mathrm{a}, \mathrm{A}}$ \\
\hline & \multirow{4}{*}{$\% 10$} & 5 & $-0.41 \pm 0.01 \mathrm{c}, \mathrm{B}$ & $-0.12 \pm 0.00^{\mathrm{b}, \mathrm{B}}$ & $-0.08 \pm 0.01^{\mathrm{a}, \mathrm{A}}$ \\
\hline & & 10 & $-0.04 \pm 0.00^{\mathrm{a}, \mathrm{A}}$ & $0.05 \pm 0.05^{\mathrm{a}, \mathrm{B}}$ & $-0.13 \pm 0.24 \mathrm{a}, \mathrm{A}$ \\
\hline & & 20 & $0.17 \pm 0.08^{\mathrm{a}, \mathrm{A}}$ & $0.12 \pm 0.10^{\mathrm{a}, \mathrm{A}}$ & $-0.09 \pm 0.24^{\mathrm{a}, \mathrm{A}}$ \\
\hline & & 30 & $0.17 \pm 0.09 \mathrm{a}, \mathrm{A}$ & $0.23 \pm 0.02^{\mathrm{a}, \mathrm{A}}$ & $0.19 \pm 0.07 \mathrm{a}, \mathrm{A}$ \\
\hline \multirow{8}{*}{$\mathrm{b}^{*}$} & \multirow{4}{*}{$\% 5$} & 5 & $5.31 \pm 0.75^{\mathrm{a}, \mathrm{A}}$ & $5.07 \pm 0.30^{\mathrm{a}, \mathrm{A}}$ & $5.21 \pm 0.52^{\mathrm{a}, \mathrm{A}}$ \\
\hline & & 10 & $6.15 \pm 0.00^{\mathrm{a}, \mathrm{A}}$ & $5.59 \pm 0.28^{\mathrm{a}, \mathrm{A}}$ & $5.64 \pm 0.78^{\mathrm{a}, \mathrm{A}}$ \\
\hline & & 20 & $5.78 \pm 1.17 \mathrm{a}, \mathrm{A}$ & $6.49 \pm 1.30^{\mathrm{a}, \mathrm{A}}$ & $6.00 \pm 0.38^{\mathrm{a}, \mathrm{A}}$ \\
\hline & & 30 & $6.16 \pm 0.20^{\mathrm{a}, \mathrm{A}}$ & $6.26 \pm 0.50^{\mathrm{a}, \mathrm{A}}$ & $6.19 \pm 0.30^{\mathrm{a}, \mathrm{A}}$ \\
\hline & \multirow{4}{*}{$\% 10$} & 5 & $7.03 \pm 0.87 \mathrm{a}, \mathrm{A}$ & $6.29 \pm 0.64 \mathrm{a}, \mathrm{A}$ & $6.31 \pm 0.66^{\mathrm{a}, \mathrm{A}}$ \\
\hline & & 10 & $6.50 \pm 0.71 \mathrm{a}, \mathrm{A}$ & $5.91 \pm 0.03^{\mathrm{a}, \mathrm{A}}$ & $6.94 \pm 0.40^{\mathrm{a}, \mathrm{A}}$ \\
\hline & & 20 & $6.91 \pm 0.45^{\mathrm{a}, \mathrm{A}}$ & $5.76 \pm 0.10 \mathrm{a}, \mathrm{A}$ & $6.51 \pm 0.78^{\mathrm{a}, \mathrm{A}}$ \\
\hline & & 30 & $6.49 \pm 0.08 \mathrm{a}, \mathrm{A}$ & $4.98 \pm 0.28 \mathrm{a}, \mathrm{A}$ & $6.17 \pm 0.69 \mathrm{a}, \mathrm{A}$ \\
\hline \multirow{8}{*}{$C^{*}$} & \multirow{4}{*}{$\% 5$} & 5 & $5.32 \pm 0.75^{\mathrm{a}, \mathrm{A}}$ & $5.07 \pm 0.31 \mathrm{a}, \mathrm{A}$ & $5.21 \pm 0.51 \mathrm{a}, \mathrm{A}$ \\
\hline & & 10 & $6.13 \pm 0.04 \mathrm{a}, \mathrm{A}$ & $5.59 \pm 0.28 \mathrm{a}, \mathrm{A}$ & $5.64 \pm 0.78^{\mathrm{a}, \mathrm{A}}$ \\
\hline & & 20 & $5.78 \pm 1.17 \mathrm{a}, \mathrm{A}$ & $6.49 \pm 1.30^{\mathrm{a}, \mathrm{A}}$ & $6.00 \pm 0.38 \mathrm{a}, \mathrm{A}$ \\
\hline & & 30 & $6.16 \pm 0.20^{\mathrm{a}, \mathrm{A}}$ & $6.26 \pm 0.50^{\mathrm{a}, \mathrm{A}}$ & $6.19 \pm 0.30^{\mathrm{a}, \mathrm{A}}$ \\
\hline & \multirow{4}{*}{$\% 10$} & 5 & $7.04 \pm 0.87 \mathrm{a}, \mathrm{A}$ & $6.29 \pm 0.64^{\mathrm{a}, \mathrm{A}}$ & $6.31 \pm 0.66^{\mathrm{a}, \mathrm{A}}$ \\
\hline & & 10 & $6.50 \pm 0.71^{\mathrm{a}, \mathrm{A}}$ & $5.91 \pm 0.03^{\mathrm{a}, \mathrm{A}}$ & $6.94 \pm 0.40^{\mathrm{a}, \mathrm{A}}$ \\
\hline & & 20 & $6.91 \pm 0.45^{\mathrm{a}, \mathrm{A}}$ & $5.76 \pm 0.10^{\mathrm{a}, \mathrm{A}}$ & $6.51 \pm 0.79 \mathrm{a}, \mathrm{A}$ \\
\hline & & 30 & $6.49 \pm 0.09 \mathrm{a}, \mathrm{A}$ & $4.99 \pm 0.28 \mathrm{a}, \mathrm{A}$ & $6.17 \pm 0.69 \mathrm{a}, \mathrm{A}$ \\
\hline
\end{tabular}


Çizelge 1. devam

Table 1. continue

\begin{tabular}{|c|c|c|c|c|c|}
\hline $\begin{array}{l}\text { Renk değerleri } \\
\text { Color values }\end{array}$ & $\begin{array}{l}\text { Kat1 oran1 } \\
\text { Solid ratio }\end{array}$ & $\begin{array}{l}\text { Süre (dk.) } \\
\text { Time (min.) }\end{array}$ & $180 \mathrm{~W}$ & $270 \mathrm{~W}$ & $360 \mathrm{~W}$ \\
\hline \multirow{8}{*}{$h^{\circ}$} & \multirow{4}{*}{$\% 5$} & 5 & $93.39 \pm 0.11^{\mathrm{a}, \mathrm{A}}$ & $91.32 \pm 0.60^{\mathrm{a}, \mathrm{A}}$ & $91.26 \pm 0.83^{\mathrm{a}, \mathrm{A}}$ \\
\hline & & 10 & $91.36 \pm 0.01^{\mathrm{a}, \mathrm{AB}}$ & $89.86 \pm 0.27 \mathrm{~b}, \mathrm{~A}$ & $91.38 \pm 0.27 \mathrm{a}, \mathrm{A}$ \\
\hline & & 20 & $90.19 \pm 1.02^{\mathrm{a}, \mathrm{B}}$ & $89.72 \pm 0.77 \mathrm{a}, \mathrm{A}$ & $89.72 \pm 0.18^{\mathrm{a}, \mathrm{A}}$ \\
\hline & & 30 & $90.59 \pm 0.19 \mathrm{a}, \mathrm{B}$ & $90.54 \pm 0.70^{\mathrm{a}, \mathrm{A}}$ & $91.19 \pm 2.12^{\mathrm{a}, \mathrm{A}}$ \\
\hline & \multirow{4}{*}{$\% 10$} & 5 & $93.28 \pm 0.47 \mathrm{a}, \mathrm{A}$ & $91.05 \pm 0.11^{\mathrm{b}, \mathrm{A}}$ & $90.71 \pm 0.18^{\mathrm{b}, \mathrm{A}}$ \\
\hline & & 10 & $90.29 \pm 0.07^{\mathrm{a}, \mathrm{B}}$ & $89.54 \pm 0.51^{\mathrm{a}, \mathrm{AB}}$ & $91.00 \pm 1.89^{\mathrm{a}, \mathrm{A}}$ \\
\hline & & 20 & $88.66 \pm 0.61^{\mathrm{a}, \mathrm{B}}$ & $88.83 \pm 0.93^{\mathrm{a}, \mathrm{B}}$ & $90.63 \pm 1.98^{\mathrm{a}, \mathrm{A}}$ \\
\hline & & 30 & $88.59 \pm 0.79^{\mathrm{a}, \mathrm{B}}$ & $87.43 \pm 0.06^{\mathrm{a}, \mathrm{B}}$ & $88.33 \pm 0.43^{\mathrm{a}, \mathrm{A}}$ \\
\hline \multirow{8}{*}{$\Delta \mathrm{E}$} & \multirow{4}{*}{$\% 5$} & 5 & $2.59 \pm 0.96^{\mathrm{a}, \mathrm{A}}$ & $3.61 \pm 0.47^{\mathrm{a}, \mathrm{A}}$ & $3.71 \pm 0.70^{\mathrm{a}, \mathrm{A}}$ \\
\hline & & 10 & $4.88 \pm 0.02^{\mathrm{a}, \mathrm{A}}$ & $4.88 \pm 0.67 \mathrm{a}, \mathrm{A}$ & $4.15 \pm 0.63^{\mathrm{a}, \mathrm{A}}$ \\
\hline & & 20 & $4.44 \pm 0.45^{\mathrm{a}, \mathrm{A}}$ & $5.07 \pm 1.05^{\mathrm{a}, \mathrm{A}}$ & $5.09 \pm 0.17 \mathrm{a}, \mathrm{A}$ \\
\hline & & 30 & $4.67 \pm 1.15^{\mathrm{a}, \mathrm{A}}$ & $4.06 \pm 0.35^{\mathrm{a}, \mathrm{A}}$ & $4.17 \pm 1.37 \mathrm{a}, \mathrm{A}$ \\
\hline & \multirow{4}{*}{$\% 10$} & 5 & $4.34 \pm 1.40^{\mathrm{a}, \mathrm{A}}$ & $6.83 \pm 0.58^{\mathrm{a}, \mathrm{A}}$ & $5.92 \pm 0.84^{\mathrm{a}, \mathrm{A}}$ \\
\hline & & 10 & $6.58 \pm 0.84^{\mathrm{a}, \mathrm{A}}$ & $6.97 \pm 0.98^{\mathrm{a}, \mathrm{A}}$ & $5.81 \pm 1.22^{\mathrm{a}, \mathrm{A}}$ \\
\hline & & 20 & $6.71 \pm 1.19^{\mathrm{a}, \mathrm{A}}$ & $5.31 \pm 1.16^{\mathrm{a}, \mathrm{A}}$ & $5.75 \pm 1.04^{\mathrm{a}, \mathrm{A}}$ \\
\hline & & 30 & $5.91 \pm 0.322^{\mathrm{a}, \mathrm{A}}$ & $6.84 \pm 0.39 \mathrm{a}, \mathrm{A}$ & $7.04 \pm 0.55^{\mathrm{a}, \mathrm{A}}$ \\
\hline
\end{tabular}

Aynı kolonda farklı harfler (a, b vd.) güce göre istatistiksel olarak farklıdır ( $P \leq 0.05)$. Aynı kolonda farklı harfler (A, B vd.) süreye göre istatistiksel olarak farklıdır $(P \leq 0.05)$.

Columns with different letters (a, b i.e.) are significantly different $(P \leq 0.05)$ with respect to power. Columns with different letters (A, B i.e.) are significantly different $(P \leq 0.05)$ with respect to time.

Ultrases destekli ekstraksiyon yöntemi ile elde edilen ekstraklara ait renk değerleri ise Çizelge 2'de verilmiştir. L* değerlerinin sabit kat1 oranında, artan ekstraksiyon süresine bağlı olarak istatistiksel açıdan önemli derecede değişmediği bulunmuştur $(P>0.05)$. Aynı katı oranlarında, artan ekstraksiyon süresine bağlı olarak elde edilen $a^{*}$ değerleri azalırken, $b^{*}$ değerlerinde ise artış olduğu görülmüştür $(P<0.05)$. $a^{*}$ değerlerindeki bu azalış kırmızılık değerinin azaldığını göstermektedir. Ruiz-Rodríguez vd. (2014) tarafından yapılan çalışmada, alıç meyvesinin yüksek antosiyanin içeriğine (en yüksek pelargonidin-3-glukozit) sahip olduğu belirtilmiştir. Çalışmamızdaki $a^{*}$ değerlerindeki azalışın sebebi, ekstakte edilen kırmızı renkli antosiyaninlerin, artan ekstraksiyon süresiyle degradasyona uğraması olabilir. Bunun yanı sıra, artan süre ile TFM miktarında artış olması kırmızı renkli fenoliklerin dışında başka fenolik maddelerin ekstrakte edilmesiyle ilișkilendirilebilir. C* değerlerinin aynı sürelerdeki artan katı oranına bağlı olarak genellikle arttı̆̆ ve bu artışın istatistiksel açıdan önemli olduğu görülmüştür $(P<0.05)$. Bu durum yukarıda belirtildiği gibi artan ekstraksiyon süresi ile birlikte fenolik maddelerin ekstraksiyonun artmasindan kaynaklanabilir. Her iki katı oranı için $\Delta \mathrm{E}$ değerleri incelendiğinde ise farklı ekstraksiyon süreleri arasındaki farklar istatistiksel açıdan anlamlı bulunmamıştır $(P>0.05)$. Bunun yanında $\mathrm{h}^{\circ}$ değerlerine bakıldığında ise $\% 5$ katı oranı için artan sürenin etkisi istatistiksel açıdan önemli bulunurken $(P<0.05), \% 10$ katı oranı için artan sürenin istatistiksel olarak anlamsız olduğu görülmüştür $(P>0.05)$.

Kontrol grubuna ait $\% 5$ ve $\% 10$ katı oranı için sirasiyla $L^{*}$ değerleri $34.32 \pm 0.16$ ve $34.08 \pm 0.02$; $a^{*}$ değerleri $-0.30 \pm 0.04$ ve $-0.34 \pm 0.01 ; b^{*}$ değerleri $2.93 \pm 0.03$ ve $3.55 \pm 0.02$; $C^{*}$ değerleri $2.95 \pm 0.03$ ve $3.56 \pm 0.02 ; h^{\circ}$ değerleri ise $95.87 \pm 0.65$ ve $95.47 \pm 0.19$ olarak bulunmuştur. Maserasyon, MDE ve UDE yöntemleri ile elde edilen renk değerleri karşılaştırıldığında, her iki katı oranında da, maserasyon ve UDE yöntemi ile elde edilen örneklerin $L^{*}$ değerleri daha fazla bulunmuştur. Diğer bir ifadeyle, maserasyon ve UDE yöntemi ile elde edilen ekstraktların daha açık bir renge sahip olduğu görülmüştür. $\mathrm{Bu}$ 
bulgu, maserasyon ve UDE yöntemi ile elde edilen TFM miktarının, MDE yöntemi ile elde edilen miktara oranla daha az olmasi ile örtüşmektedir.

Çizelge 2. UDE ile elde edilen ekstraktların $L^{*}, a^{*}, b^{*}, C^{*}, h^{\circ}$ ve $\Delta E$ değerlerinin farklı sonikasyon süreleri $(1,10,20,30,50$ ve $70 \mathrm{dk}$.) ve katı oranları (\%5 ve \%10) ile değişimi

Table 2. Variation of $L^{*}, a^{*}, b^{*}, C^{*}, b^{\circ}$ and $\triangle E$ values of $U A E$ samples with sonication time $(1,10,20,30,50$ and $70 \mathrm{~min}$.) and solid ratios (5\% and 10\%)

\begin{tabular}{|c|c|c|c|}
\hline \multirow{3}{*}{$\begin{array}{l}\text { Renk değerleri } \\
\text { Color values }\end{array}$} & \multirow{3}{*}{$\begin{array}{l}\text { Süre (dk.) } \\
\text { Time (min.) }\end{array}$} & \multicolumn{2}{|c|}{$\begin{array}{l}\text { Kat1 Oran1 } \\
\text { Solid ratio }\end{array}$} \\
\hline & & $\% 5$ & $\% 10$ \\
\hline & & $5 \%$ & $10 \%$ \\
\hline \multirow{6}{*}{$\mathrm{L}^{*}$} & 1 & $35.15 \pm 0.20^{\mathrm{a}, \mathrm{A}}$ & $34.17 \pm 0.42^{\mathrm{a}, \mathrm{A}}$ \\
\hline & 10 & $33.82 \pm 0.32^{\mathrm{a}, \mathrm{A}}$ & $33.00 \pm 0.63^{\mathrm{a}, \mathrm{A}}$ \\
\hline & 20 & $34.53 \pm 0.10^{\mathrm{a}, \mathrm{A}}$ & $33.15 \pm 1.87 \mathrm{a}, \mathrm{A}$ \\
\hline & 30 & $35.02 \pm 0.02^{\mathrm{a}, \mathrm{A}}$ & $34.07 \pm 0.46^{\mathrm{a}, \mathrm{A}}$ \\
\hline & 50 & $34.51 \pm 0.06^{\mathrm{a}, \mathrm{A}}$ & $34.16 \pm 0.51^{\mathrm{a}, \mathrm{A}}$ \\
\hline & 70 & $34.58 \pm 0.17 \mathrm{a}, \mathrm{A}$ & $34.03 \pm 0.05^{\mathrm{a}, \mathrm{A}}$ \\
\hline \multirow{6}{*}{$a^{*}$} & 1 & $-0.02 \pm 0.00^{\mathrm{a}, \mathrm{A}}$ & $-0.18 \pm 0.04^{\mathrm{a}, \mathrm{B}}$ \\
\hline & 10 & $-0.13 \pm 0.04 \mathrm{ab}, \mathrm{A}$ & $-0.28 \pm 0.04^{a b, A}$ \\
\hline & 20 & $-0.17 \pm 0.00^{\mathrm{ab}, \mathrm{A}}$ & $-0.26 \pm 0.17^{\mathrm{ab}, \mathrm{A}}$ \\
\hline & 30 & $-0.26 \pm 0.02^{\mathrm{b}, \mathrm{A}}$ & $-0.46 \pm 0.04^{\mathrm{ab}, \mathrm{B}}$ \\
\hline & 50 & $-0.27 \pm 0.02^{\mathrm{b}, \mathrm{A}}$ & $-0.50 \pm 0.04^{\mathrm{b}, \mathrm{B}}$ \\
\hline & 70 & $-0.25 \pm 0.02^{\mathrm{b}, \mathrm{A}}$ & $-0.52 \pm 0.03^{\mathrm{b}, \mathrm{B}}$ \\
\hline \multirow{6}{*}{$\mathrm{b}^{*}$} & 1 & $2.42 \pm 0.04^{\mathrm{b}, \mathrm{B}}$ & $4.60 \pm 0.04^{\mathrm{b}, \mathrm{A}}$ \\
\hline & 10 & $4.43 \pm 0.01^{\mathrm{a}, \mathrm{B}}$ & $6.62 \pm 0.54 \mathrm{ab}, \mathrm{A}$ \\
\hline & 20 & $4.14 \pm 0.00^{\mathrm{a}, \mathrm{A}}$ & $6.10 \pm 0.88^{\mathrm{ab}, \mathrm{A}}$ \\
\hline & 30 & $4.33 \pm 0.00^{\mathrm{a}, \mathrm{B}}$ & $6.67 \pm 0.58^{\mathrm{ab}, \mathrm{A}}$ \\
\hline & 50 & $4.56 \pm 0.22^{\mathrm{a}, \mathrm{A}}$ & $6,51 \pm 0.53^{\mathrm{ab}, \mathrm{A}}$ \\
\hline & 70 & $4.81 \pm 0.05^{\mathrm{a}, \mathrm{B}}$ & $6.83 \pm 0.12^{\mathrm{a}, \mathrm{A}}$ \\
\hline \multirow{6}{*}{$\mathrm{C}^{*}$} & 1 & $2.42 \pm 0.07 \mathrm{~b}, \mathrm{~B}$ & $4.60 \pm 0.04^{\mathrm{b}, \mathrm{A}}$ \\
\hline & 10 & $4.43 \pm 0.02^{\mathrm{a}, \mathrm{B}}$ & $6.63 \pm 0.54 \mathrm{ab}, \mathrm{A}$ \\
\hline & 20 & $4.14 \pm 0.01^{\mathrm{a}, \mathrm{A}}$ & $6.11 \pm 0.87 \mathrm{ab}, \mathrm{A}$ \\
\hline & 30 & $4.34 \pm 0.01^{\mathrm{a}, \mathrm{B}}$ & $6.69 \pm 0.58^{\mathrm{ab}, \mathrm{A}}$ \\
\hline & 50 & $4.57 \pm 0.45^{\mathrm{a}, \mathrm{A}}$ & $6.52 \pm 0.53^{\mathrm{ab}, \mathrm{A}}$ \\
\hline & 70 & $4.82 \pm 0.11^{\mathrm{a}, \mathrm{A}}$ & $6.85 \pm 0.12^{\mathrm{a}, \mathrm{A}}$ \\
\hline \multirow{6}{*}{$h^{\circ}$} & 1 & $90.45 \pm 0.17 \mathrm{~b}, \mathrm{~B}$ & $92.27 \pm 0.46^{\mathrm{a}, \mathrm{A}}$ \\
\hline & 10 & $91.67 \pm 0.99 \mathrm{ab}, \mathrm{A}$ & $92.42 \pm 0.53^{\mathrm{a}, \mathrm{A}}$ \\
\hline & 20 & $92.34 \pm 0.09^{\mathrm{ab}, \mathrm{A}}$ & $92.56 \pm 1.98^{\mathrm{a}, \mathrm{A}}$ \\
\hline & 30 & $93.43 \pm 0.65^{\mathrm{a}, \mathrm{A}}$ & $93.99 \pm 0.65^{\mathrm{a}, \mathrm{A}}$ \\
\hline & 50 & $93.36 \pm 0.08^{\mathrm{a}, \mathrm{B}}$ & $94.37 \pm 0.01^{\mathrm{a}, \mathrm{A}}$ \\
\hline & 70 & $92.96 \pm 0.52^{\mathrm{a}, \mathrm{A}}$ & $94.32 \pm 0.16^{\mathrm{a}, \mathrm{A}}$ \\
\hline \multirow{6}{*}{$\Delta \mathrm{E}$} & 1 & $1.02 \pm 0.36^{\mathrm{a}, \mathrm{A}}$ & $1.10 \pm 0.07 \mathrm{a}, \mathrm{A}$ \\
\hline & 10 & $1.65 \pm 0.22^{\mathrm{a}, \mathrm{A}}$ & $3.27 \pm 0.72^{\mathrm{a}, \mathrm{A}}$ \\
\hline & 20 & $1.24 \pm 0.04^{\mathrm{a}, \mathrm{A}}$ & $2.93 \pm 1.36 \mathrm{a}, \mathrm{A}$ \\
\hline & 30 & $1.57 \pm 0.01^{\mathrm{a}, \mathrm{A}}$ & $3.14 \pm 0.58^{\mathrm{a}, \mathrm{A}}$ \\
\hline & 50 & $1.65 \pm 0.43^{\mathrm{a}, \mathrm{A}}$ & $2.98 \pm 0.51^{\mathrm{a}, \mathrm{A}}$ \\
\hline & 70 & $1.91 \pm 0.15^{\mathrm{a}, \mathrm{B}}$ & $3.29 \pm 0.12^{\mathrm{a}, \mathrm{A}}$ \\
\hline
\end{tabular}

Aynı kolonda farklı harfler (a, b vd.) süreye göre istatistiksel olarak farkhder $(P \leq 0.05)$. Aynı kolonda farklı harfler (A, B vd.) katı oranına göre istatistiksel olarak farklıdır $(P \leq 0.05)$.

Columns with different letters ( $a, b$ i.e.) are significantly different $(P \leq 0.05)$ with respect to time. Columns with different letters $(A, B$ i.e.) are significantly different $(P \leq 0.05)$ with respect to solid ratio. 
Sonuç olarak bu çalışmada, MDE yönteminde, 180,270 ve $360 \mathrm{~W}$ mikrodalga güçleri kullanılarak 5, 10, 20 ve 30 dakikalarda elde edilen TFM miktarları değerlendirildiğinde, birim katı madde miktarına düşen çözücü miktarı arttıkça TFM miktarında da artış görülmüştür. Başka bir deyişle, düşük katı oranına sahip örneklerde TFM miktarı daha yüksek bulunmuştur. MDE yöntemi ile alıç meyvesinin TFM miktarının $9.31 \pm 0.15 \mathrm{mg}$ GAE/g kuru madde değeri ile en yüksek olduğu koşullar, $\% 5$ katı oranı, $270 \mathrm{~W}$ mikrodalga gücü ve ekstraksiyon süresinin 20 dakika olduğu durumda elde edilmiştir. Bu durum $270 \mathrm{~W}$ gücünde 20 . dakikadan sonra artan sicaklikla birlikte fenolik maddelerin zarar görmesi, daha kısa sürelerin ise fenolik maddelerin ekstraksiyonu için yetersiz kalması ile açıklanabilir. En düşük TFM miktarı ise $\% 5$ katı oranı, $360 \mathrm{~W}$ mikrodalga gücü ve ekstraksiyon süresinin 5 dakika olduğu koșullarda 4.39 $\pm 0.89 \mathrm{mg}$ GAE/g kuru madde olarak bulunmuştur. UDE yönteminde alıç meyvesinin TFM miktarı en yüksek $5.34 \pm 0.68 \mathrm{mg}$ GAE/g kuru madde olarak \%5 katı oranında ve sonikasyon süresinin 70 dakika olduğu koşullarda elde edilmişken, en düşük değer $1.98 \pm 0.31 \mathrm{mg}$ GAE/g kuru madde olarak, aynı katı oranında sonikasyon süresinin 1 dakika olduğu koșulda bulunmuştur. Kontrol grubunda ise alıç meyvesinde TFM değeri $\% 5$ kat1 oran1 için $3.00 \pm 0.10 ; \% 10$ katı oranı için $2.49 \pm 0.15 \mathrm{mg}$ GAE/g kuru madde olarak tespit edilmiştir. Bu üç yöntemin TFM miktarları karşılaştırdığında, MDE yöntemi ile maserasyona kiyasla 3 kat, UDE yöntemine göre yaklaşık $\% 74$ oranında daha yüksek TFM içeren ekstraktlar elde edilmiştir. Bunun yanı sıra, MDE yöntemi ile ekstraksiyon süresi, UDE yöntemine kıyasla 3.5 kat daha azalmıştır. Renk değerleri kıyaslandığında, TFM sonuçlarına paralel olarak, L* değerinin MDE yönteminde daha düşük, yani daha koyu renk oluşturduğu belirlenmiştir. UDE yönteminde katı oranın artması $a^{*}$ değerlerinin azalmasına, b* değerlerinin ise artmasina neden olmuştur. Tüm bu veriler 1șığında, MDE yönteminin alıç meyvesinden TFM ekstraksiyonu için daha uygun bir yöntem olduğu sonucuna varılmıştır.

\section{ÇIKAR ÇATIŞMASI BEYANI}

Yazarların başka kişiler ve/veya kurumlar ile çıkar çatışması bulunmamaktadır.

\section{YAZAR KATKILARI}

MSY, NK ve GME deneylerin planlanmasi ile yapilışında görev almışlar ve taslak metni oluşturmuşlardır. OS ve AI danışman olarak çalışma fikrinin oluşmasında, deney tasarımının oluşturulmasinda, verilerin değerlendirilmesinde ve taslağın kontrolünde/düzenlenmesinde görev almışlardır. Yazarlar makalenin son halini okumuş ve onaylamıstır.

\section{TEŞEKKÜR}

Çalışma sırasındaki desteklerinden dolayı Büşra Erdem, Bilge Deveci, Ayșe Bıyıklı, Seda Taşkın, Birgül Erbay, Gülce Kabasakaloğlu, Kübra Kayıhan ve Sanam Mustafaeva'ya teşekkür ederiz.

\section{KAYNAKLAR}

Akbulut, M., Çoklar, H. (2008).Physicochemical and rheological properties of sesame pastes (Tahin) processed from hulled and unhulled roasted sesame seeds and their blends at various levels. J Food Process Eng, 31: 488-502, https://doi.org/10.1111/j.17454530.2007.00162.x.

Alifakı, Y.Ö., Şakıyan Demirkol, Ö., İsci Yakan, A. (2018). Gilaburu (Vibirium Opulus K.) Meyvesinden Fenolik Bileşiklerin Ultrason Destekli Ekstraksiyonu. Gıda, 43(5): 846-855, https://doi.org/10.15237/gida.GD18069.

Alifak1, Y.Ö. (2019). Gilaburu (Viburnum opulus L.) Meyvesinden Yeni Yöntemlerle Fenolik Bileşenlerin Ekstraksiyonu ve Gilaburu Tozunun Mikroenkapsülasyonu. Doktora tezi, Ankara Üniversitesi Fen Bilimleri Enstitüsü, 291 s.

Awad, T.S., Moharram, H.A., Shaltout, O.E., Asker, D., Youssef, M.M. (2012). Applications of ultrasound in analysis, processing and quality control of food: A review. Food Res Int, 48: 410427, $\quad$ https://doi.org/10.1016/ j.foodres.2012.05.004.

Baltacioğlu, H., Şahin, E. M., Karadağ, E.D. (2019). Şeftali Posasından Ultrason ve Mikrodalga Destekli Ekstraksiyon Yöntemleriyle Fenolik 
Bileşiklerin Eldesi. ÖHÜ Müh. Bilim. Derg, 8(2): 875-881, $\quad$ https://doi.org/10.28948/ ngumuh.570250.

Baysal, T., İçier, F. (2012). Guda Mühendisliğinde Isıl Olmayan Teknolojiler. Nobel Yayıncilık, Ankara.

Both, S., Chemat, F., Strube, J. (2014). Extraction of polyphenols from black tea - Conventional and ultrasound assisted extraction. Ultrason Sonochem, 21(3): 1030-1034, https://doi.org/10.1016/ j.ultsonch.2013.11.005.

Chang, Q, Zuo, Z., Harrison, F., Chow, M.S.S. (2002). Hawthorn. J Clin Pharmacol, 42(6): 605612 , https://doi.org/10.1177/ 00970002042006003.

Chemat, F., Zill-E-Huma, Khan, M.K. (2011). Applications of ultrasound in food technology: Processing, preservation and extraction. Ultrason Sonochem, 18(4): 813-835, https://doi.org/ 10.1016/j.ultsonch.2010.11.023.

Çoklar, H. Akbulut, M. Kılınç. S, Yıldırım, A., Alhassan, I. (2018). Effect of Freeze, Oven and Microwave Pretreated Oven Drying on Color, Browning Index, Phenolic Compounds and Antioxidant Activity of Hawthorn (Crataegus orientalis) Fruit. Not Bot Horti Agrobo, 46(2): 449456, https://doi.org/10.15835/nbha46211027.

Çoklar, H., Akbulut, M. (2016). Olgunlaşma ile Alıç Meyvesinin (Crataegus orientalis) Antioksidan Aktivite, Toplam Fenolik Madde ve Fenolik Profilindeki Değişim. Meyve Bilimi, 3: 30-37.

Dahmoune, F., Spigno, G., Moussi, K., Remini, H., Cherbal, A., Madani, K. (2014). Pistacia lentiscus leaves as a source of phenolic compounds: Microwave-assisted extraction optimized and compared with ultrasound-assisted and conventional solvent extraction. Ind Crops Prod, 61: 31-40, https://doi.org/10.1016/j.indcrop. 2014.06.035.

Fanari, F., Muntoni, G., Dachena, C., Carta, R., Desogus, F. (2020). Microwave Heating Improvement: Permittivity Characterization of Water-Ethanol and Water- $\mathrm{NaCl}$ Binary Mixtures. Energies, 13(18): 4861, https://doi.org/ 10.3390/en13184861.
Ghasempour, N., Elhami Rad, A.H., Javanmard, M., Azarpazhouh, E., Amin, M. (2019). Optimization of conditions of ultrasoundassisted extraction of phenolic compounds from orange pomace (Citrus sinensis). Int J Biol Chem, 12(2): 1019, https://doi.org/10.26577/ijbch-2019-v2-2.

Ghitescu, R.E., Volf, I., Carausu, C., Bühlmann, A.M., Gilca, I.A., Popa, V.I. (2015). Optimization of ultrasound-assisted extraction of polyphenols from spruce wood bark. Ultrason Sonochem 22: 535-541, $\quad$ https://doi.org/10.1016/ j.ultsonch.2014.07.013.

Goula, A.M., Thymiatis, K., Kaderides, K. (2016). Valorization of grape pomace: Drying behavior and ultrasound extraction of phenolics. Food Bioprod Process, 100: 132-144, https://doi.org/ 10.1016/j.fbp.2016.06.016.

Ignat, I., Volf, I., Popa, V.I. (2011). A critical review of methods for characterisation of polyphenolic compounds in fruits and vegetables. Food Chem 126: 1821-1835, https://doi.org/ 10.1016/j.foodchem.2010.12.026.

Kaderides, K., Papaoikonomou, L., Serafim, M., Goula, A.M. (2019). Microwave-assisted extraction of phenolics from pomegranate peels: Optimization, kinetics, and comparison with ultrasounds extraction. Chem Eng Process, 137: 111, https://doi.org/10.1016/j.cep.2019.01.006.

Khan, M.K., Abert- Vian, M., Fabiano-Tixier, A, Dangles, O., Chemat, F. (2010). Ultrasoundassisted extraction of polyphenols (flavanone glycosides) from orange (Citrus sinensis L.) peel. Food Chem, 119(2): 851-858, https://doi.org/10.1016/j.foodchem.2009.08.04 6.

Knorr, D., Zenker, M., Heinz, V., Lee, D.U. (2004). Applications and potential of ultrasonics in food processing. Trends Food Sci Technol, 15: 261266, https://doi.org/10.1016/j.tifs.2003.12.001.

Kumari, B., Tiwari, B.K., Hossain, M.B., Rai, D.K., Brunton, N.P. (2017). Ultrasound-assisted extraction of polyphenols from potato peels: profiling and kinetic modelling. Int J Food Sci Technol, 52(6): 1432-1439, https://doi.org/ 10.1111/ijfs.13404. 
Kusuma, H.S., Altway, A., Mahfud, M. (2018). Solvent-free microwave extraction of essential oil from dried patchouli (Pogostemon cablin Benth) leaves. J Ind Eng Chem, 58: 343-348, https://doi.org/10.1016/j.jiec.2017.09.047.

Kutlu, N., Bicak, C., Ekinci, D., Kilic, E., Erdem, N., Isci, A., Sakiyan, Ö. (2018). Application of response surface methodology to optimize microwave-assisted extraction of total phenolic compounds from Caucasian whortleberry (Vaccinium arctostaphylos). Gida, 43 (2): 264-272, https://doi.org/10.15237/gida.GD17087.

Lapornik, B., Prosek, M., Wondra, A.G. (2005). Comparison of extracts prepared from plant byproducts using different solvents and extraction time. J Food Eng, 71: 214-222, https://doi.org/10.1016/j.jfoodeng.2004.10.036.

Lopez-Avila, V. (1999). Sample preparation for environmental analysis. Crit Rev Anal Chem, 29(3): 195-230, https://doi.org/10.1080/10408349891199392.

Lovrić, V., Putnik, P., Kovačević, D.B., Jukić, M., Dragović-uzelac, V. (2017). Effect of MicrowaveAssisted Extraction on the Phenolic Compounds and Antioxidant Capacity of Blackthorn Flowers. Food Technol Biotech, 55(2): 243-250, https://doi.org/10.17113/ftb.55.02.17.4687.

Meda, V., Orsat, V., Raghavan, V. (2017). Microwave heating and the dielectric properties of foods. In The Microwave Processing of Foods (Second Edition), Woodhead:Cambridge, ISBN; 978-008-100528-6.

Nitthiyah, J., Nour, A.K.R., Akindoyo, J. (2017). Microwave Assisted Hydrodistillation - An Overview of Mechanism and Heating Properties. Aust J Basic\& Appl Sci, 11(3): 22-29.

Özbek H.N., Koçak Yanık, D., Fadıloğlu, S., Keskin Çavdar, H., Göğüş., F. (2018). Microwave-assisted extraction of non-polar compounds from pistachio hull and characterization of extracts. Grasas Aceites, https://doi.org/10.3989/gya.0217181.

Özcan, M., Hacıseferogulları, H., Marakoglu, T., Arslan, D. (2005). Hawthorn (Crataegus spp.) fruit: some physical and chemical properties. J Food
Eng, 69: 409- 415, https://doi.org/10.1016/j.jfoodeng.2004.08.032.

Pan, X., Niu, G., Liu, H. (2003). Microwaveassisted extraction of tea polyphenols and tea caffeine from green tea leaves. Chem Eng Process. 42: 129-133, https://doi.org/10.1016/S02552701(02)00037-5.

Pettinato, M., Casazza, A.A., Ferrari, P.F., Palombo, D., Perego, P. (2019). Eco-sustainable recovery of antioxidants from spent coffee grounds by microwave-assisted extraction: Process optimization, kinetic modeling and biological validation. Food Bioprod Process, 114: 3142, https://doi.org/10.1016/j.fbp.2018.11.004.

Pico, Y. (2013). Ultrasound-assisted extraction for food and environmental samples. Trends Anal Chem, Vol. 43: 84-99, https://doi.org/10.1016/ j.trac.2012.12.005.

Pingret, D., Fabiano-Tixier, A.S., Chemat, F. (2013). Degradation during application of ultrasound in food processing: A review. Food Control, 31(2): 593-606, https://doi.org/10.1016/ j.foodcont.2012.11.039.

Piyasena, P., Mohareb, E., McKellar, R.C. (2003). Inactivation of microbes using ultrasound: A review, Int J Food Microbiol, 87(3): 207-216, https://doi.org/10.1016/S0168-1605(03)000758.

Popa, V.I., Dumitru, M., Volf, I., Anghel, N. (2008). Lignin and polyphenols as allelochemicals. Indl Crops Prod, 27: 144-149, https://doi.org/10.1016/j.indcrop.2007.07.019.

Quiroz-Reyes, C.N., Aguilar-Mendez, M., Ramirez-Ortis, M., Ronquillo-De Jesus, E. (2013). Comparative study of ultrasound and maceration techniques for the extraction of polyphenols from cocoa beans (Theobroma cacao L.). Revista Mexicana de Ingenier'ia Qu'mica, 12(1): 11-18.

Radojković, M., Moreira, M.M., Soares, C., Fátima Barroso, M., Cvetanović, A., Švarc-Gajić, J., Morals, S. Delerue-Matos, C. (2018). Microwaveassisted extraction of phenolic compounds from Morus nigra leaves: optimization and characterization of the antioxidant activity and phenolic composition. J Chem Technol Biotechnol, 
93: 1684-1693, https://doi.org/10.1002/ jctb.5541.

Ruiz-Rodríguez, B.M., de Ancos, B., SánchezMoreno, C., Fernández-Ruiz, V., de Cortes Sánchez-Mata, M., Camara, M., Tardio, J. (2014). Wild blackthorn (Prunus spinosa L.) and hawthorn (Crataegus monogyna Jacq.) fruits as valuable sources of antioxidants. Fruits, 69(1), 61-73. https://doi.org/10.1051/fruits/2013102.

Seçmen, Ö., Gemici, Y., Leblebici, Y., Görk, G., Bekat, L. (1989). Tohumlu Bitkiler Sistematiği, E.Ü. Fen Fak. İzmir. No: 116, 2. Bask1, 396.

Swamy, G. J., Muthukumarappan, K. (2017). Optimization of continuous and intermittent microwave extraction of pectin from banana peels. Food Chem, 220: 108-114, https://doi.org/10.1016/j.foodchem.2016.09.19 7.

Wei, Z.F., Zhao, R.N., Dong, L.J., Zhao, X.Y., Su, J.X., Zhao, M., Li, L., Bian, Y. J., Zhang, L.J. (2018). Dual-cooled solvent-free microwave extraction of Salvia officinalis L. essential oil and evaluation of its antimicrobial activity. Ind Crops Prod, 120: 71-76, https://doi.org/10.1016/ j.indcrop.2018.04.058.
Xia, T., Zhang, C., Oyler, N.A., Chen, X. (2013). Hydrogenated $\mathrm{TiO}_{2}$ nanocrystals: a novel microwave absorbing material. Adv Mater, 25(47): 6905-6910, https://doi.org/10.1002/ adma.201303088.

Xu, D.P., Zheng, J., Zhou, Y., Li, Y., Li, S. and Li, H.B. (2017). Ultrasound-assisted extraction of natural antioxidants from the flower of Limonium sinuatum: Optimization and comparison with conventional methods. Food Chem, 217: 552-559, https://doi.org/10.1016/j.foodchem.2016.09.01 3.

Yeşilören Akal, G. (2019). Siyah Havuç Posasindan Antosiyanin Ekstraksiyonu. Doktora tezi, Ankara Üniversitesi Fen Bilimleri Enstitüsü, 217 s.

Zhu, Z., Guan, Q., Guo, Y., He, J., Liu, G., Li, S., Barba, F.J., Jaffrin M.Y. (2016). Green ultrasound-assisted extraction of anthocyanin and phenolic compounds from purple sweet potato using response surface methodology. Int Agrophys, 30: 113-122, https://doi.org/ 10.1515/intag-2015-0066. 